\title{
Economic burden of Communicable and Non-communicable Diseases in Jamaica: Is our research focus where it should be?
}

Christine Maria Fray-Aiken ${ }^{1}$

1 University of Technology, Jamaica

\section{BACKGROUND}

\section{The Caribbean Region}

The Caribbean has moved from under-nutrition and communicable diseases to over-nutrition and chronic non-communicable diseases (CNCDs) being the major public health problems over the last several decades. The Region has seen great improvements due to immunization coverage which has resulted in the eradication of several communicable diseases e.g. poliomyelitis (last outbreak, 1982), measles (not diagnosed since 1991), and rubella (not diagnosed since 2002) [1]. The average life expectancy in Latin America and the Caribbean has risen from 51 to 76 years in the last few decades along with an improvement in nutrition quality. Simultaneously, the Region has seen a switch in dietary intake from vegetable to animal protein as well as an increase in the percent of energy coming from fat intake $[2,3]$.

\section{Jamaica}

Like the rest of the Caribbean, Jamaica has changed from under-nutrition and communicable diseases being the major causes of death and disability to CNCDs over the last five decades [4]. In 2000, the prevalence of obesity among Jamaican 15-74 year olds was $9.6 \%$ among males and $29.9 \%$ among females [5]. Cerebrovascular diseases, ischemic heart diseases, hypertensive diseases, heart failure, diabetes mellitus and coronary heart disease/other forms of heart disease were among the ten leading causes of death in Jamaica during 1998 [6]. These diseases are all linked to obesity. Between 2001 and 2005 , there were no cases of measles, polio, diphtheria, rubella, congenital rubella, or neonatal tetanus due to immunization in Jamaica. In addition, between 1950 and 2012, life expectancy increased from 58.5 years to 74 years $[7,3]$.

Therefore, there has been a definite change in the overall health profile at the Regional level. This transition also occurred in Jamaica which supports the point that CNCDs are not diseases of affluence, as developing countries now bear the major burden [8]. With this public health transition, it is therefore quite understandable that the focus of research over the years, moved from under-nutrition and communicable diseases to over-nutrition and obesity and obesity-related diseases (CNCDs). However, where should our research focus be now?

\section{DISCUSSION}

\section{Present coexistence of both Communicable and Non-communicable Diseases}

At the Regional level, CNCDs have been consistently determined the most common causes of death in analyses done every 5 years from 1985 to 2000 with heart diseases, cancers, cerebrovascular diseases, and diabetes mellitus constituting the four leading causes of deaths [1]. In 2000, HIV/AIDS climbed to $5^{\text {th }}$ position (from $8^{\text {th }}$ position in 1995) [1].

In 2012, twenty-six percent of the life years lost (LYL) in Jamaica was due to communicable diseases. This was $10 \%$ higher than the Regional average (Figure 1) [3]. Sixty-one percent of the LYL for Jamaica in 2012 was due to CNCDs. This was close to the Regional average of $66 \%$ (Figure 1) [3]. HIV/
Corresponding author Christine Fray-Aiken caiken@utech.edu.jm

\section{Disclosure}

No funding was provided for this editorial. 


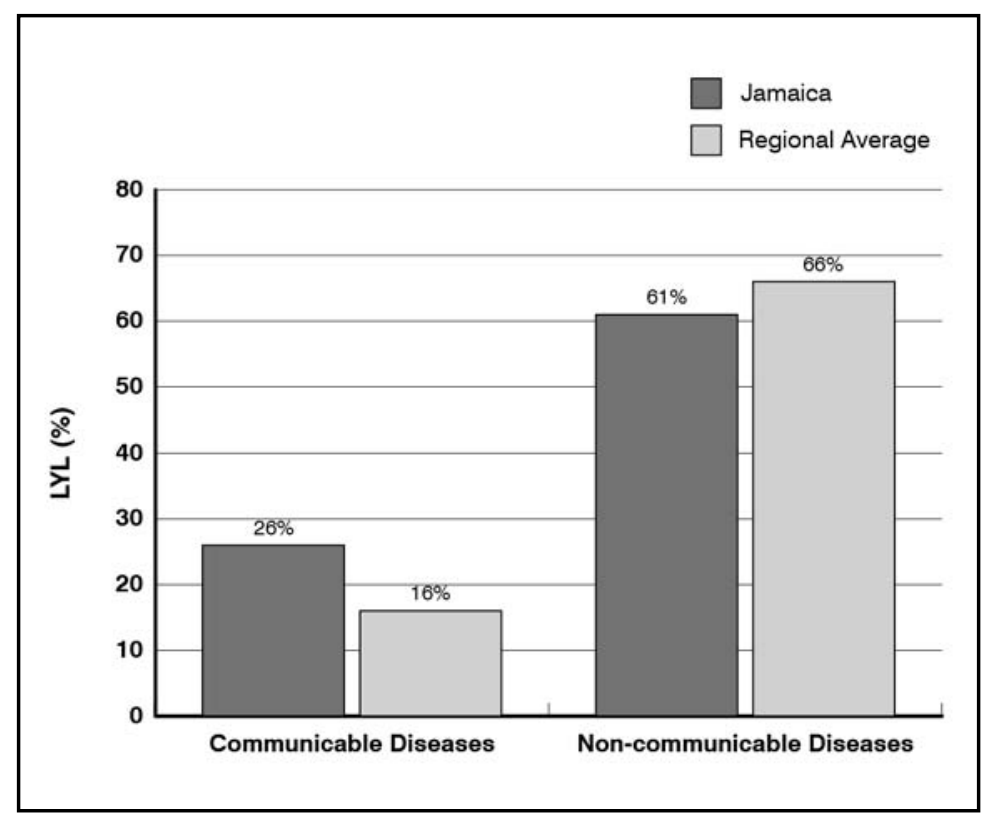

Figure 1. Distribution of life years lost (LYL) by causes in 2012 [3]

AIDS is the major communicable disease that causes concern in the Region [1]. Another communicable diseases of growing importance is tuberculosis. The increase in the number of cases of tuberculosis observed is thought to be due to a combination of factors that include poverty, malnutrition, and the HIV/AIDS epidemic [1].

The HIV/AIDS is at an epidemic level in Jamaica [9]. The prevalence of HIV per 100,000 population for Jamaica is 3 times and twice that at the Regional and Global level respectively (Table I) [3]. An estimated 50 people have died from AIDS every month in Jamaica between 2001 and 2003 [1]. Despite extensive national and international support for activities of the National HIV/AIDS/ STI prevention and Control Programme, the number of reported cases of AIDS continues on an upward trend [10]. Overall for Jamaica, more males are reported with AIDS than females [10]. However, females in the 10-14 and 15-19 years age group are twice and three times as likely to be infected as males in their respective age groups [10]. Between 1999 and 2002, HIV death rates doubled for females from 15.8 to 30.7 per 100,000 population; and increased for males from 26.9 to 44.9 per 100,000 [9].

\begin{tabular}{lccc}
\hline & \multicolumn{3}{c}{ Prevalence (per 100,000 population) } \\
\cline { 2 - 4 } & Jamaica & Regional average & Global average \\
\hline HIV & 1,024 & 315 & 511 \\
Tuberculosis & 9.5 & 40 & 169 \\
\hline
\end{tabular}

Table I. Prevalence of HIV and tuberculosis per 100,000 population for Jamaica, the Region and worldwide [3]

\section{Cost burden attributable to chronic non-communicable diseases}

Obesity and its related chronic diseases are seen as a result of lifestyle changes due to economic development. However, it is important to note that country-wide economic development is not necessarily needed for the lifestyle changes required to fuel weight gain to occur [11]. Instead the obesity-diabetes epidemic being observed in many poor and middle-income countries is a result of the nature of social development [11]. Therefore, a country does not have to necessarily be affluent to have an economic burden due to obesity or chronic diseases. Jamaica is an example of such a country. In Jamaica, there were 1,092 premature deaths due to cardiovascular disease in 1999 resulting in a total of 41,157 life years lost (LYL) [1]. While $61 \%$ of the LYL in Jamaica in 2012 was due to CNCDs (Figure 1) [3].

In 2001, the total economic burden of diabetes in Jamaica amounted to J\$10.18 billion/ US\$221 million (at 2001 rates) with the costs of medications, hospitalization and diagnostics accounting for about $56 \%, 13 \%$ and $12 \%$ of this cost respectively [12]. The total economic burden of hypertension for Jamaica during 2001 was J\$12.26 billion/US\$266 million. Costs of medications and diagnostics accounted for $45 \%$ and $26 \%$ of this cost respectively [12].

\section{Cost burden attributable to communicable diseases}

Sixteen percent of the life years lost (LYL) in 2012 in the Region was due to communicable diseases (Figure 1) [3]. For the period 1985 to 2000 , the years of productive life lost (YPLL) in the Region increased by some $22 \%$ largely due to the effect of HIV/AIDS. This was observed most notably in males 20-44 years old [1]. We are losing many persons during their economically productive years throughout the Caribbean.

Communicable diseases were responsible for $26 \%$ of the life years lost (LYL) in Jamaica in 2012 (Figure 1) [3]. In addition, for HIV/ AIDS during 2004, Jamaican males and females lost 25,000 and 9,000 disability-adjusted life years (DALY) respectively [13].

\section{Where do we go from here?}

Historically, Jamaica has moved from under-nutrition and communicable diseases to over-nutrition and obesity and obesity-related diseases. As a result, many Researchers have studied obesity and chronic non-communicable diseases resulting in invaluable information. However, HIV/AIDS is also of importance and needs more attention in the research arena. 


\begin{tabular}{lcc|cc|cc}
\hline \multirow{2}{*}{$\begin{array}{c}\text { Age group } \\
\text { (years) }\end{array}$} & \multicolumn{2}{c}{ HIV/AIDS } & \multicolumn{2}{c}{ Nutritional Deficiency } & \multicolumn{2}{c}{ Chronic Non-communicable Diseases } \\
\cline { 2 - 7 } & Male & Female & Male & Female & Male & Female \\
\hline $0-14$ & 39 & 38 & 62 & 54 & 187 & 173 \\
$15-59$ & 1,006 & 431 & 30 & 21 & 1,077 & 1,219 \\
$60+$ & 69 & 25 & 83 & 138 & 5,032 & 6,566 \\
\hline
\end{tabular}

Table II. Number of deaths in Jamaica in 2008 [15]

In addition, we may be seeing the re-emergence of under-nutrition. In a comparison of 2010 survey results with those from 2008 among Jamaican children under five years old, an increase in the estimated prevalence of under-nutrition and a decline in the estimated prevalence of over-nutrition was observed [14]. This is likely due to the Jamaican economy which continued to contract in 2010, as a result of the prolonged effect of the global economic recession [14]. Many Jamaicans have been on salary-freeze since the beginning of the recession in 2008. The numbers of deaths in Jamaica in 2008 among $0-14$ year olds as result of nutritional deficiency were 1.6 and 1.4 times the number of deaths due to HIV/AIDS for males and females respectively (Table II) [15]. In addition, the numbers of deaths in Jamaicans over 60 years as result of nutritional deficiency were 1.2 and 5.5 times the number of deaths due to HIV/AIDS for males and females respectively (Table II) [15]. It is important to note that for Jamaicans 15-59 years, the number of deaths due to HIV/AIDS for males was almost similar to the number of deaths due to CNCDs for males. While for females, the number of deaths was $35 \%$ of the amount due to CNCDs for females (Table II) [15]. Bear in mind that the data for HIV/AIDS account for one disease condition, whereas the data for CNCDs account for a combination of diseases e.g. diabetes, hypertension, and cardiovascular disease.

\section{CONCLUSIONS}

The public health transition continues. We currently have economic burdens due to obe- sity and obesity-related diseases i.e. chronic non-communicable diseases, as well as due to HIV/AIDS. In addition, we may be observing the re-emergence of under-nutrition in Jamaica due to the economic recession. At present, the amount of research studies that can be found on CNCDs for Jamaica far outnumber what can found for HIV/AIDS. It is important that researchers cover all areas well so that knowledge of the direct and indirect costs to healthcare systems and society can be obtained. This would enable the making of relevant policy decisions for appropriate cost-effective interventions in the Jamaican Health Sector.

\section{RECOMMENDATIONS}

- The burden of CNCDs remains very high in the Jamaican population and may be increasing. However, the prevalence of communicable diseases, notably HIV/ AIDS, is also high and may be increasing as well. A study of the economic burden of both is needed.

- Periodic surveys should be done to provide evidence on prevalence and trends of chronic non-communicable diseases and HIV/AIDS.

- The leading causes of death in Jamaica are CNCDs, followed by HIV/AIDS. The resulting economic burden from both is due to lifestyle behaviour. Perhaps education or policy interventions can be undertaken.

- With the present ongoing recession, it is time to start paying attention again to under- nutrition.

\section{REFERENCES}

1. PAHO/WHO; CARICOM. Report of the Caribbean Commission on Health and Development. Kingston: Ian Randle Publishers, 2006

2. Gaziano TA, Reddy KS, Paccaud F, et al. Cardiovascular Disease. In: Jamison DT, Breman JG, Measham AR, et al. Disease Control Priorities in Developing Countries. 2nd Edition. Oxford University Press \& The World Bank, 2006

3. WHO. Jamaica: Health Profile Country profile: Jamaica, 2014. Available at: http://www.who.int/countries/jam/en/ (last accessed May 18, 2014) 
4. Wilks R, Younger N, Tulloch-Reid M, et al. Jamaica Health and Lifestyle Survey 2007-8. Technical Report. Epidemiology Research Unit, Tropical Medicine Research Institute, University of the West Indies, Mona, 2008

5. Wilks R, Zohoori N, Ashley D, et al. The Jamaican Healthy Lifestyle Survey. Kingston: TMRI-UWI/Ministry of Health, 2000

6. McCaw-Binns A, Holder Y, Spence K, et al. Multisource method for determining mortality in Jamaica: 1996 and 1998. Department of Community Health \& Psychiatry, University of the West Indies. International Biostatistics Information Services. Division of Health Promotion \& Protection, Ministry of Health, Jamaica. Statistical Institute of Jamaica, 2002

7. Department of Economic and Social Affairs Population Division, United Nations, (UN). World population ageing 1950-2050. New York: United Nations, 2002.

8. WHO. Noncommunicable disease and poverty: the need for pro-poor stategies in the Western Pacific Region: a review. Geneva: World Health Organization, 2006

9. PAHO/WHO. Jamaica. In: Cruz A (ed). Health in the Americas 2007. Washington, D.C.: Pan American Health Organization, 2007

10. Planning Institute of Jamaica, Ministry of Finance and Planning, Bank of Jamaica. Jamaica's Medium Term Socio Economic Policy Framework 2004-2007. 2005.

11. Durazo-Arvizu RA, Luke A, Cooper RS, et al. Rapid increases in obesity in Jamaica, compared to Nigeria and the United States. BMC Public Health 2008; 8: 133; http://dx.doi.org/10.1186/1471-2458-8-133

12. Abdulkadri AO, Cunningham-Myrie C, Forrester T. Economic Burden of Diabetes and Hypertension in CARICOM States. Social and Economic Studies 2009; 58: 175-97

13. WHO, Department of measures and health information. Mortality and Burden of Disease Estimates for WHO Member States in 2004. WHO, 2009

14. STATIN, PIOJ. Jamaica survey of living conditions: report 2010. Kingston: The Statistical Institute of Jamaica (STATIN) and The Planning Institute of Jamaica (PIOJ), 2012

15. WHO. Summary death estimates 2008. WHO, 2011 